\title{
A TRAVESSIA NA FAIXA DE PEDESTRE EM BRASÍLIA (DF/ BRASIL): EXEMPLO DE UMA INTERVENÇÃO CULTURAL
}

\author{
WALKING THE CROSSWALK IN BRASÍLIA (DF/ BRAZIL): \\ A CULTURAL INTERVENTION EXAMPLE
}

\author{
Vívica Lé SÉNÉCHAL-Machado \\ FACULDADE PITÁGORAS, BELO HORIZONTE, BRASIL \\ Joño Claudio Todorov
}

UNIVERSIDADE CATÓLICA DE GOIÁS E INSTITUTO DE EDUCAÇÃO SUPERIOR DE BRASÍLIA, BRASIL

\begin{abstract}
RESUMO
Desde 1997, praticamente todos os motoristas de Brasília (DF/Brasil) respeitam a faixa de pedestre. Essa mudança de prática cultural ocorreu devido a uma campanha local, envolvendo importantes agências sociais, cujos representantes reuniam-se no Fórum Permanente pela Paz no Trânsito, organizado pela Universidade de Brasília (UnB). O presente trabalho descreveu as ações dessas agências que promoveram uma intervenção cultural e que resultou na nova prática cultural do respeito à faixa de pedestre. Através da análise de documentos e da realização de entrevistas buscou-se reconstruir a história dessa campanha, com o objetivo de identificar, analisar e interpretar as contingências comportamentais entrelaçadas responsáveis por tal intervenção cultural. Esse fenômeno social foi discutido à luz dos conceitos de macrocontingência e metacontingência.

Palavras-chave: prática cultural, faixa de pedestre, intervençáo cultural, macrocontingência e metacontingência.
\end{abstract}

\section{ABSTRACT}

The study of social phenomena has increasingly awakened the interest and concern of Behavior Analysts. Since 1997, practically all drivers living in Brasília (DF/ Brazil) respect pedestrian crosswalks. This changing of cultural practice happened as a result of a local campaign involving important social agencies, whose representatives came together in a Permanent Forum for Peace on Traffic organized by the University of Brasilia $(\mathrm{UnB})$. The present study described the agency's actions that promoted a cultural intervention and resulted in the new cultural practice of yielding to pedestrians. Through the analysis of documents and interviews this study sought to rebuild the history of this campaign, with the purpose of identifying, analyzing and interpreting the interlocking behavioral contingencies responsible for such cultural intervention. This social phenomenon was discussed in relation to the concepts of macrocontingencies and metacontingencies.

Key words: cultural practice, crosswalks, cultural interventions, macrocontingencies, metacontingencies.

"... até que, um louco varrido, um sujeito desmiolado, resolven fazer a proposta mais louca do mundo, mais maluca, mais inaceitável, mais indecente e mais perigosa do mundo. Ele se levantou e disse: 'olha, nós vamos respeitar a faixa de pedestres agora. O pedestre na faixa vai ter preferência.' Foi um pânico geral! Todo mundo ficou pasmo, inclusive os técnicos. 'Essa cara tá louco?'. O nome desse sujeito é Renato Azevedo. E

O presente trabalho é uma versão abreviada da dissertação de mestrado do primeiro autor, apresentada em agosto de 2007, ao Programa de Pós-graduação em Ciências do Comportamento da Universidade de Brasília (UnB), sob orientação do segundo autor. A primeira autora agradece à Capes e à Finatec pelos financiamentos concedidos. Email: vivicasenechal@gmail.com. 
ai comecon o tal da faixa de pedestres." Prof. Dr. David Duarte Lima (UnB).

A colocação acima ilustra, muito bem, o que Skinner (1971/1983) afirma sobre o planejamento de uma cultura: muitas vezes é uma proposta ambiciosa, quase sempre considerada utópica no sentido pejorativo.

\section{Cultura e Práticas Sociais}

A Psicologia, de forma geral, considera a cultura como uma forma de viver compartilhada por um grupo de pessoas, que inclui costumes, valores, suposições, tradições, etc. que influenciam e guiam o comportamento, tornando possível às pessoas sobreviver em seu meio (Berry 1992, citado por Huffman, Vernoy e Vernoy, 2001).

Para Skinner (1953/2000, 1969/1984, 1971/1983), a cultura se refere às contingências de reforçamento social que geram e mantêm o comportamento dos membros de uma cultura, cuja existência vai além do período de vida dos membros do grupo. Normalmente, essas contingências são formuladas por meio de regras e leis que constituem os costumes e tradições, habituais de um povo. Ou seja, é um conjunto particular de condições no qual um grande número de pessoas se desenvolve e vive. Dessa maneira, o ambiente social é aquilo que, tipicamente, chamamos de cultura.

Glenn (2004) se refere à cultura como "padrões de comportamentos aprendidos transmitidos socialmente, assim como os produtos de tais comportamentos (objetos, tecnologias, organizações, etc)" (p.139). E às práticas culturais como sendo "padrões similares de conteúdo comportamental, usualmente resultados de similaridades nos ambientes" ( $p$. 140). Essa similaridade no conteúdo operante do repertório de várias pessoas, ao longo da passagem do tempo, é o que garante nomear esse fenômeno como uma prática cultural. As práticas culturais envolvem, então, consistência no comportamento de muitos indivíduos. Variações de práticas culturais estão sempre ocorrendo, já que estas envolvem o comportamento de gerações sucessivas de indivíduos que vivem em ambientes comportamentais um pouco diferentes dos indivíduos da geração anterior (Glenn, 1988).

\section{MacrocontingênCIA E MetacontingÊnCIA}

De acordo com Skinner (1981), a cultura evolui quando suas práticas contribuem para o sucesso do grupo praticante em resolver seus problemas. E ressalta que é o efeito sobre o grupo, e não as conseqüências reforçadoras para os membros individuais, que é responsável pela evolução e seleção de uma cultura.

A análise e compreensão dos fenômenos sociais, então, não se limitam às contingências que descrevem o comportamento operante de um único indivíduo, implicando a utilização de uma outra unidade de análise para a compreensão de tais fenômenos (Andery, Micheletto \& Sério, 2005: Glenn, 1986).

A partir das contribuições de Skinner (1948/1978, 1953/2000, 1957/1978, 1961, 1969/1984, 1971/1983, 1974/1982, 1986), Glenn (1991) afirma que as contingências comportamentais dão conta da evolução e manutenção das unidades comportamentais (seleção ontogenética) e que as metacontingências dão conta da evolução e manutenção das unidades culturais (seleção cultural).

Glenn (1986) apresenta, ainda, o conceito de metacontingência diferenciando-o do conceito de contingência de reforçamento, com o intuito de fazer uma distinção entre a seleção do comportamento operante a seleção de práticas culturais. As metacontingências descrevem relações funcionais no nível cultural - envolvem 
relações de contingência entre contingências comportamentais entrelaçadas e um resultado comum a longo prazo.

Contingências entrelaçadas são mais do que a soma de contingências individuais, por produzirem resultados que não são possíveis de serem obtidos pelos indivíduos se comportando isoladamente. Dessa forma, as contingências comportamentais entrelaçadas são contingências sociais nas quais o comportamento e os produtos comportamentais de cada membro funcionam como evento ambiental com o qual o comportamento dos outros indivíduos interage. O comportamento de cada pessoa possui um duplo papel: de ação e de ambiente para a ação de outros (Glenn, 1988, 1989, 1991).

O conceito de metacontingência especifica que os processos cultural e comportamental ocorrem em diferentes níveis de organização, embora apresentem processos de seleção análogos. Nenhum processo comportamental novo está envolvido. $\mathrm{Na}$ seleção cultural, os resultados culturais não selecionam o comportamento dos indivíduos que fazem parte do entrelaçamento de contingências. Eles selecionam as contingências comportamentais entrelaçadas. O resultado cultural tem a mesma relação com as contingências entrelaçadas que as conseqüências comportamentais têm com o operante. Assim, a evolução cultural constituise não de atos individuais repetidos, mas sim da repetição de contingências comportamentais entrelaçadas que funcionam como uma unidade integrada, produzindo resultados que afetam a probabilidade futura da recorrência do entrelaçamento (Glenn, 1988, 1991, 2004).

Entretanto, a formulação do conceito de metacontingência, como relações funcionais entre contingências comportamentais entrelaçadas e um resultado comum a longo prazo (Glenn, 1986, 1988 e 1991), sofreu algumas modificações, ao longo dos anos, permitindo um melhor entendimento da relação entre as contingências comportamentais entrelaçadas, o produto gerado desse entrelaçamento e o ambiente selecionador.

Glenn (2004), Glenn e Mallot (2004) e Mallot e Glenn (2006) destacam a importância da distinção entre o produto e a conseqüência de um comportamento, apesar de, às vezes, eles poderem ser o mesmo. Assim como o comportamento operante, que envolve um produto comportamental, as contingências comportamentais entrelaçadas também geram um produto, que é um produto agregado resultado de recorrentes operantes inter-relacionados de várias pessoas. E, assim como o comportamento operante é seguido por uma conseqüência, responsável pela recorrência ou não desse operante, as contingências comportamentais entrelaçadas, e seu produto, também são selecionados por uma conseqüência final - efeito no ambiente externo - responsável pela recorrência ou não desse entrelaçamento. O ambiente externo é o recipiente do produto agregado e funciona como o ambiente selecionador das contingências entrelaçadas. Esse entrelaçamento não se repetirá mais caso não haja demanda por seus produtos.

O conceito de metacontingência, então, explicitado, descreve:

Relações contingentes entre recorrentes contingências comportamentais entrelaçadas, que tem um produto agregado, e conseqüências funcionais baseadas na natureza desse produto. A repetição das contingências comportamentais entrelaçadas de duas ou mais pessoas constitui uma linhagem cultural sendo selecionada (Mallot \& Glenn, 2006, p. 38).

Mallot e Glenn (2006) distinguem duas fontes de produtos agregados (produtos culturais). Uma fonte é a interação organizada 
e recorrente de múltiplos indivíduos, dos quais o comportamento inter-relacionado resulta em um produto agregado. Nesse caso, o produto requer não só o comportamento de todos os indivíduos, mas também as contingências entrelaçadas recorrentes que mantêm a interrelação entre os comportamentos de diferentes pessoas. Esse é o produto agregado envolvido em uma relação de metacontingência, mantido por uma linhagem cultural que é selecionada. Outra fonte se dá através da soma dos produtos de pessoas se comportando individualmente e recorrentemente. Esse é o produto agregado envolvido em uma relação de macrocontingência. Macrocontingência, então, diz dá relação entre comportamentos recorrentes, e funcionalmente independentes, de vários indivíduos, e um produto agregado resultante da soma dos produtos comportamentais individuais. Ou seja, é a relação entre linhagens operantes, que são repetições de um comportamento operante como resultado de contingências de seleção comportamentais, e seu produto agregado (Glenn, 2004; Mallot \& Glenn, 2006). Desse modo, na macrocontingência há apenas uma única contingência sendo repetida milhares de vezes, por diferentes pessoas. A repetição sucessiva de uma mesma contingência por muitas pessoas caracteriza uma determinada prática cultural, que produz um efeito cumulativo a longo prazo, como o resultado do somatório dos efeitos do comportamento de cada um. Nesse sentido, uma característica importante da macrocontingência é que seu efeito cumulativo é aditivo. Quanto mais difundida a prática, maior o efeito cumulativo.

Na macrocontingência não há seleção cultural. O produto cultural não seleciona o comportamento individual recorrente das pessoas. $\mathrm{O}$ produto não funciona como uma conseqüência que mantém o comportamento que constitui a prática. As únicas contingências de seleção en- volvidas na macrocontingência são contingências operantes. A mudança cultural é uma mudança de comportamento de vários indivíduos, como resultado de contingências comportamentais de seleção operando no comportamento de cada indivíduo. Nesse caso, para produzir alguma intervenção cultural sobre um efeito cumulativo é preciso encontrar maneiras de alterar, individualmente, o maior número possível do mesmo comportamento dos vários participantes (Glenn, 2004, Mallot \& Glenn, 2006).

Intervenções culturais são designadas para alterar condições geradas pelo comportamento, inter-relacionado ou não, de muitos indivíduos. Quando estes comportamentos geram um produto agregado que afeta outras pessoas, ou a própria sobrevivência de uma cultura, este produto se torna um problema social, podendo ser perigoso e causar prejuízos à saúde, segurança ou felicidade de um grande número de pessoas. Assim, nessas situações, uma intervenção cultural se faz necessária e justificável (Mallot \& Glenn, 2006).

Intervenções em uma metacontingência e em uma macrocontingência são diferentes. Intervenções culturais para alterar o produto agregado em macrocontingências têm como alvo somente mudanças comportamentais (linhagens operantes específicas). Intervenções culturais em uma metacontingência têm como alvo de interesse contingências comportamentais recorrentes que produzem um produto agregado (linhagens culturais) e que resultam em inputs (efeitos no ambiente externo) que mantêm essas recorrências (Mallot \& Glenn, 2006). Dessa maneira, planejamentos culturais são importantes para que se evite a necessidade de grandes intervenções culturais reparadoras.

O processo de aprendizagem de comportamentos sociais, assim como o de comportamentos não sociais, depende do arranjo de contingências ambientais que envolvem o 
estabelecimento de relações entre o comportamento dos organismos e as conseqüências ambientais de tais ações.

Alguns desses processos comportamentais, envolvidos na aprendizagem de grande parte dos comportamentos sociais que constituem práticas culturais, estão relacionados à modelação, a exposição direta às contingências de reforço e ao papel das regras no controle do comportamento.

\section{Planejamento Cultural}

De acordo com Skinner (1969/1984):

Uma cultura bem planejada é um conjunto de contingências de reforço, sob o qual os membros se comportam de acordo com procedimentos que mantêm a cultura, capacitam-na a enfrentar emergências e modificam-na de modo a realizar essas mesmas coisas mais eficientemente no futuro (p. 207).

Quando Skinner (1953/2000) afirma sobre o planejamento "deliberado" de uma cultura, ele quer dizer que uma nova prática deve ser produzida por causa de suas conseqüências futuras mais favoráveis. Mas essas conseqüências futuras nunca são suficientes para justificar tal planejamento. Para se entender melhor um planejamento é preciso identificar os eventos ambientais anteriores que fazem com que uma mudança cultural seja advogada. Ou seja, é preciso a identificação do problema social que esteja causando danos à sociedade para que se justifique uma intervenção (Mallot \& Glenn, 2006).

Mattaini (1995) argumenta que, para que uma determinada prática cultural seja alterada, em função de efeitos que podem afetar a viabilidade de uma cultura, são necessárias intervenções planejadas sobre os comportamentos dos membros constituintes da prática.
O planejamento de intervenções culturais deve, então, buscar identificar as contingências operantes dos comportamentos dos indivíduos, estejam eles se comportando de forma interrelacionada ou não. O comportamento do indivíduo é a base a partir da qual as práticas culturais emergem em uma cultura. Os processos pelos quais as práticas são estabelecidas e mantidas consistem das relações comportamentais básicas. Não há nenhum processo comportamental novo. Por isso se faz necessário identificar os princípios comportamentais subjacentes a estes comportamentos (Mattaini, 1995, 1996; Mallot, 1988).

Alguns desses processos comportamentais, envolvidos na aprendizagem e modificação de grande parte dos comportamentos sociais que constituem as práticas culturais, estão relacionados à modelação, a exposição direta às contingências de reforço e ao papel das regras no controle do comportamento.

\section{A Campanha pela Paz no Trânsito e pelo Respeito à Faixa de Pedestres}

O deslocamento a pé é um dos mais importantes meios de transporte urbano, sendo o mais utilizado para percorrer pequenas distâncias ou servindo como complemento de viagens realizadas por outros modos de transporte (Castro, Santos, Yamanaka \& Rosa, 1997; Melo \& Moreira, 2005).

As faixas de pedestres, um dos principais elementos que compõem o sistema de trânsito dos usuários, apesar de serem concebidas para sinalizar de forma segura e não ambígua os locais de travessia de pedestres, são foco de polêmica por serem, sistematicamente, desrespeitadas por motoristas e, também, pelos próprios pedestres (Vialle e Junior, 2003).

Brasília/DF, nos anos de 1995 e 1996, era uma das cidades brasileiras mais violentas 
no trânsito, não só pelo grande número de acidentes e vítimas fatais, mas também pela violência dos desastres e pelo grande índice de pedestres atropelados. O número de atropelamentos nesses anos representava, respectivamente, $49,8 \%$ e 47,3\% do número total de acidentes, com morte, em todo Distrito Federal. Números que revelavam a situação grave em que se encontrava a relação pedestre - veículo, em Brasília/DF, uma cidade planejada para a rápida e fácil circulação de carros, com pistas largas e longas, que favoreciam o abuso da velocidade e dificultavam a travessia das ruas pelos pedestres.

Apesar de a lei estar prevista no Código de Trânsito Brasileiro, desde 1966, pode-se afirmar que, praticamente, ela nunca fora cumprida por motoristas e pedestres brasileiros. Porém, na cidade de Brasília/DF, desde o ano de 1997, tem sido possível observar o respeito à faixa de pedestres. Esse cumprimento da lei foi possível a partir de uma mobilização social que promoveu a união entre a mídia, o governo e a sociedade civil brasiliense em prol de um mesmo objetivo: a Paz no Trânsito.

O presente trabalho teve como objetivo identificar e descrever as ações realizadas por pessoas e instituições, que se mostraram fundamentais na criação e condução das Campanhas pela Paz no Trânsito e pelo Respeito à Faixa de Pedestre, nos anos de 1996 e 1997, respectivamente, em Brasília-DF, que estabeleceram mudanças significativas no repertório comportamental de motoristas e pedestres dessa cidade. Mais especificamente, objetivou-se identificar, analisar e interpretar as contingências comportamentais entrelaçadas responsáveis pelo estabelecimento da prática cultural de travessia na faixa de pedestres e, ainda, discutir esse fenômeno à luz dos conceitos de macrocontingência e metacontingência, buscando apontar a relevância de tais conceitos na interpretação teórica desse fenômeno social.

\section{MÉTODO}

\section{Fontes}

Foram consultadas para a coleta de dados as seguintes fontes de informação: 1) Mídia Escrita: Jornal Correio Braziliense e Jornal de Brasília; 2) Fórum Permanente pela Paz no Trânsito (UnB); 3) Detran - DF; 4) Entrevistas; 5) Outras fontes (contatos e conversas informais).

\section{Procedimento de coleta de dados e materiais obtidos}

Midia escrita: Correio Braziliense e Jornal de Brasilia. Foram selecionadas e registradas, em uma planilha, as datas e manchetes de todas as notícias sobre os vários aspectos do trânsito da cidade de Brasília-DF (acidentes, leis, índices estatísticos, ações do Detran-DF, perigos e riscos), divulgadas pelo Correio Braziliense, nos anos de 1995 a 1999, e pelo Jornal de Brasília, nos anos de 1996 e 1997. Todas as edições do jornal foram consultadas, página por página, pela pesquisadora. Esse levantamento foi possível através do acesso aos arquivos dos Centros de Documentação de ambos os jornais, que dispõem de todas as edições do jornal encadernadas.

Fórum Permanente pela Pazno Trânsito (UnB). Através do acesso a um arquivo pertencente ao Decanato de Extensão da UnB foram obtidos documentos que continham projetos, datas, listas de presença, pautas e atas das várias reuniões realizadas pelo grupo do Fórum, no prédio da Reitoria da UnB.

Detran-DF. Foram obtidos documentos nos seguintes setores que compõem a instituição: Biblioteca (trabalhos referentes ao respeito à faixa de pedestre); Setor de Campanhas (folhetos sobre campanhas educativas); Divisão de Educação no Trânsito (folhetos sobre o trabalho do grupo de teatro) e Núcleo de Pesquisa e Tratamento de Dados (dados estatísticos).

Entrevistas. Foram realizadas entrevistas com algumas das pessoas consideradas mui- 
to importantes, à época, para o processo de implementação das Campanhas pela Paz no Trânsito e pelo Respeito à Faixa de Pedestre. Essas entrevistas foram abertas, sem nenhum roteiro formalmente elaborado anteriormente pela pesquisadora, de forma a evitar qualquer possível direcionamento das respostas dos entrevistados. Todas as entrevistas foram gravadas em mídia de áudio digital e, posteriormente, transcritas.

Outras fontes. Obtenção de documentos através de encontros e conversas informais junto ao Ex-Diretor do Detran e ao ExComandante do Batalhão de Trânsito da PM.

\section{Procedimento de análise de dados}

Todas as informações obtidas foram usadas com o objetivo de reconstruir, o mais fielmente possível, um relato histórico dos acontecimentos relativos às Campanhas da Paz no Trânsito e do estabelecimento do Respeito à Faixa de Pedestre, em Brasília-DF, nos anos de 1996 e 1997.

Após construir o relato, a pesquisadora buscou relacioná-lo com os dados estatísticos obtidos junto ao setor de Núcleo de Pesquisa e Tratamento de Dados, do Detran-DF, de forma a identificar correlações entre ações, acontecimentos e índices estatísticos.

Por fim, o relato histórico foi analisado e interpretado de acordo com os princípios da Análise do Comportamento buscando, particularmente, interpretar o estabelecimento da prática cultural do Respeito à Faixa de Pedestre à luz dos conceitos teóricos de macrocontingência e metacontingência.

\section{RESULTADOS E DISCUSSÃO}

\section{Histórico}

Em julho de 1995, o Governo do Distrito Federal (GDF) criou o Programa de Segurança para o Trânsito. No ano seguinte, em outubro de
1996, o GDF alterou e ampliou esse Programa, transformando-o no Programa Paz no Trânsito.

No intervalo de tempo entre a criação dos dois Programas lançados pelo GDF, o jornal Correio Braziliense, em agosto de 1996, lançou uma campanha contra a violência no trânsito brasiliense. Em quase todos os dias do mês de agosto, houve publicação de, pelo menos, uma matéria sobre a violência no trânsito. Tal seqüência de notícias marcou o início da Campanha pela Paz no Trânsito, no mês de agosto, e foi essencial para a mobilização e envolvimento de toda a sociedade brasiliense, que reagiu à campanha iniciada, com a organização de uma passeata pela Paz no Trânsito, no mês de setembro, reunindo mais de 25 mil pessoas.

É interessante observar que a criação do novo programa do governo para as questões de trânsito, lançado em outubro de 1996, parece ter sofrido fortes influências da Campanha pela Paz no Trânsito, iniciada pelo Correio Braziliense, em agosto de 1996. Um indicador de tal influência foi a nomeação desse novo programa - Programa Paz no Trânsito - utilizando a denominação já encabeçada pelo Correio Brasiliense em sua campanha. Além disso, uma das ações ampliadas no novo programa se referiu à organização de campanhas de publicidade para conscientização dos cidadãos sobre os problemas no trânsito.

Após o período de criação e encabeçamento da Campanha pela Paz no Trânsito pelo Correio Braziliense, no mês de dezembro, este jornal delegou a continuidade do movimento à Universidade de Brasília (UnB), que organizou o Fórum Permanente pela Paz no Trânsito, ficando este grupo, a partir de então, responsável pelos passos seguintes dessa campanha. Os membros do Fórum eram representantes de diversos segmentos do governo e da sociedade: Grupo Executivo do Programa Paz no Trânsito do Governo (Secretaria de Transportes, 
de Segurança Pública e de Comunicação, do GDF); mídia (Correio Braziliense, Rede Globo, Jornal de Brasília, Rede Bandeirantes, CBN); entidades religiosas (LBV, Federação Espírita, Comissão de Justiça e Paz da Arquidiocese de Brasília, Congregação Presbiteriana); Polícia Militar; Detran e Universidade de Brasília.

Na segunda reunião do Fórum, em janeiro de 1997, foi apresentada uma proposta para a Educação de Pedestres para o Trânsito. Essa proposta incluía o fazer com que a faixa de pedestre fosse respeitada em Brasília-DF. Para que essa proposta fosse efetivada era necessária a aprovação do Fórum, o que aconteceu. Como ali havia representantes tanto do governo, como da sociedade civil, a aprovação, portanto, representava a posição de ambos os segmentos. Esse acordo entre governo e sociedade parece ter sido fundamental para evitar a aparência de ação do Governo-DF como uma atitude autoritária, pois as decisões passaram a ser descentralizadas das mãos do governo e passaram a ser tomadas por uma equipe da sociedade civil, juntamente com representantes do Governo. Tal diversificação promoveu, como afirma Skinner (1953/2000), uma distribuição do controle do comportamento entre muitas agências que tinham pouco em comum e que por isso, provavelmente, não se juntariam em uma unidade despótica.

Depois de aprovada a proposta foi iniciado, então, o trabalho educativo do Batalhão de Trânsito da Polícia Militar na Campanha pelo Respeito à Faixa de Pedestre. Durante os três primeiros meses do ano de 1997, a Polícia Militar ficou encarregada de instruir motoristas e pedestres sobre a nova prática, através do fornecimento de regras e modelos com campanhas educativas nas ruas e escolas. Nesse período, nenhuma multa era aplicada e apenas advertências eram apresentadas aos motoristas. De acordo com Todorov (1987), quando mudanças são propostas é preciso um trabalho de determinação de regras específicas, de providenciar consequências imediatas para o seguimento delas e de avaliação dessas regras. É necessário recorrer ao estabelecimento de regras, pois de acordo com Mallot (1988), as contingências que formam a base da maioria das culturas são contingências que não agem diretamente sobre o comportamento, e especificam resultados atrasados.

Mais uma vez, o Correio Braziliense, entre outras mídias, como o Jornal de Brasília e a Rede Globo, entrou em cena para a divulgação e mobilização da população para a adesão à campanha do respeito à faixa. Várias notícias, principalmente durante o mês de março de 1997, foram publicadas, alertando a população sobre a nova prática e as campanhas educativas que vinham sendo feitas. Nesses casos, as notícias podem ter o papel de regras, funcionando como estímulos que alteram a função de outros estímulos - discriminativos, neutros ou reforçadores (Sanabio \& Abreu-Rodrigues, 2002; Schlinger, 1993). A análise do relato de algumas manchetes de notícias nesse período permitiu identificá-las como regras funcionando como estímulos alteradores de função, para o comportamento do motorista de parar antes da faixa de pedestre. As notícias parecem ter estabelecido a função discriminativa de alguns estímulos tais como a própria faixa de pedestres, o pedestre com a intenção de atravessar a rua, a placa de sinalização da faixa, e outros. Estes estímulos adquiriram funções discriminativas e evocativas como resultado das regras noticiadas e passaram a controlar, de forma mais eficiente, o comportamento do motorista, produzindo consequências reforçadoras como não se envolver em acidentes, não atropelar pedestres, entre outras.

A partir do dia 1o de abril de 1997, a lei começou a vigorar e os policiais começaram 
a multar os motoristas que desrespeitavam a preferência do pedestre na faixa. Nesse momento, as regras deixaram de ser apresentadas pela Polícia e passaram a ser oferecidas pelo próprio Estado, através do início do dever de obediência à 'lei da faixa'. O índice de multas, logo nos primeiros dias em que a lei passou a vigorar, foi considerado alto. Esse dado sugere que, para o estabelecimento do comportamento do motorista de parar na faixa de pedestre, foi necessário o uso da punição positiva através da aplicação de multas. Sustenta-se, assim, que a modelagem do comportamento por exposição direta às contingências de reforçamento caracteriza uma parte substancial da forma como se aprende comportamentos sociais (Skinner, 1969/1984).

$\mathrm{Na}$ primeira semana de abril os jornais divulgaram o grande número de multas que haviam sido aplicadas desde o dia 1o. Mais uma vez, nesse caso, as notícias podem funcionar como regras e, além de alterar a relação entre os estímulos discriminativos que estão no trânsito e os comportamentos das pessoas no trânsito, podem, também, alterar o valor reforçador de uma conseqüência. Função esta que se assemelha muito ao efeito das Operações Estabelecedoras: uma operação ambiental que altera, momentaneamente, a efetividade reforçadora de algum objeto, evento ou estímulo (Michael, 1993). A dificuldade em identificar o aumento do valor reforçador das consequências dos comportamentos dos motoristas não permitiu uma caracterização tão clara das notícias como Operações Estabelecedoras. Mas estas sugeriram um provável efeito alterador do valor reforçador de consequências como, por exemplo, parar o carro antes da faixa porque evitava multa.

Pode-se sugerir que essas notícias também serviram para que os 'leitores motoristas' aprendessem com outros motoristas que foram multados e que, por sua vez, serviram como modelo do comportamento punido por não respeitar a faixa. Dessa forma, a divulgação de notícias de motoristas sendo multados, além de ressaltar a regra do respeito à faixa, serviu, também, como um modelo eficiente que afetava muitas pessoas ao mesmo tempo, livrando-as de uma exposição direta às contingências aversivas.

O Detran, durante a Campanha pelo Respeito à Faixa, participou com a atuação dos setores de engenharia e educação. Os agentes começaram a pintar novas faixas em locais que atendessem aos critérios para sua implantação e apagar várias outras faixas que estavam localizadas em locais considerados inadequados. Também foram instaladas, a 100m de cada faixa, placas de sinalização com os dizeres "Passagem de Pedestre". Essas obras tornaram as faixas de pedestre e as placas de sinalização de faixas, estímulos discriminativos mais salientes, permitindo maior controle desses estímulos sobre o comportamento de motoristas e pedestres. Além disso, em setembro de 1997, o Detran lançou a campanha educativa "Dê Sinal de Vida", que tinha como objetivo tornar a travessia dos pedestres sobre a faixa ainda mais segura. Para isso, os pedestres deveriam realizar um sinal com o braço antes de atravessar a rua. Dessa forma, o braço estendido passou a ser mais um estímulo discriminativo que controlava o comportamento do motorista de parar o carro antes da faixa.

\section{Indices estatísticos}

Os dados estatísticos do Detran-DF demonstram, redução nos índices de atropelamentos, a partir do ano de 1995 até o ano de 1998. Os resultados mostrados nas Figuras 1 e 2 permitem analisar a evolução do trânsito de Brasília/DF, com relação ao respeito ao pedestre, que vinha sendo uma das principais vítimas da violência no trânsito. A Figura 1 mostra a 
porcentagem de atropelamentos de pedestres, em todo o Distrito Federal, em relação ao total de acidentes, com morte, por ano.

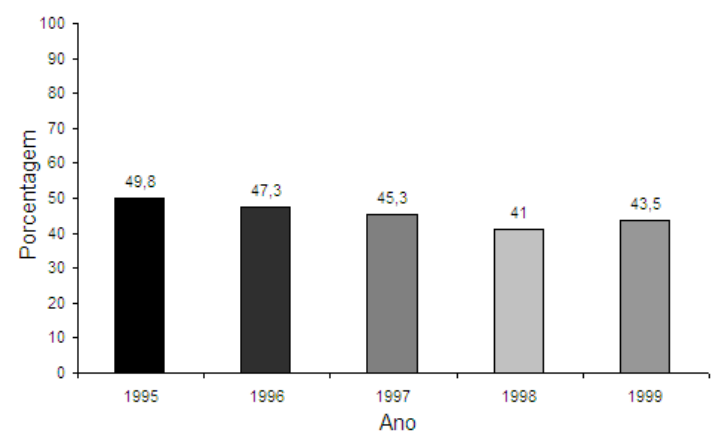

Figura 1. Porcentagem de atropelamentos de pedestres em relação ao total de acidentes ocorridos, com morte, em todo o Distrito Federal, de 1995 a 1999.

Os resultados mostram uma redução gradual da porcentagem de atropelamentos de pedestres de 1995 a 1998, destacando-se uma redução de 4,5\% de 1995 a 1997. A Figura 2 mostra o número de atropelamentos de pedestres, nas Vias Urbanas do Distrito Federal, no período de 1995 a 199

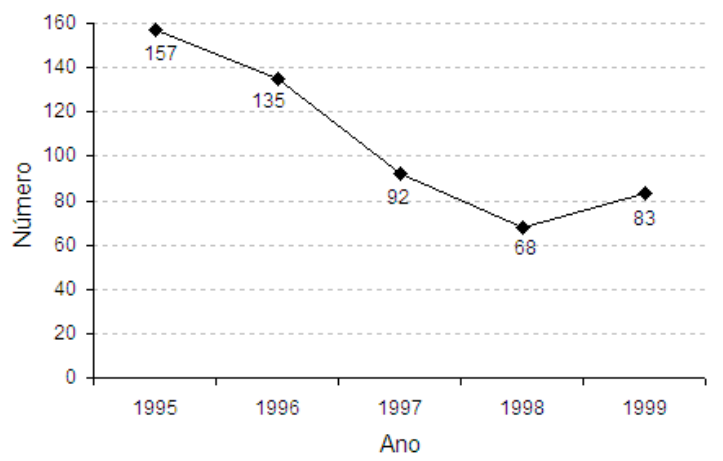

Figura 2. Número de atropelamentos de pedestres, com morte, nas Vias Urbanas, em todo Distrito Federal, de 1995 a 1999.

Uma redução de 31,9\% no número de atropelamentos fatais nas Vias Urbanas entre os anos de 1996 e 1997 fica evidenciada nos dados dessa figura, que mostra, ainda, tal redução como a maior ocorrida nos anos de 1995 a
1999. No ano de 1999 é possível observar um pequeno aumento nesses números, fato este que parece correlacionado com a mudança de governo do Distrito Federal e com o fim do Fórum Permanente pela Paz no Trânsito, no final de 1998. Essas mudanças parecem ter interferido na evolução positiva que vinha ocorrendo no trânsito da cidade, desfazendo a parceria formada até então entre governo e sociedade civil, acordada e mantida pelo Fórum.

\section{Macrocontingência e metacontingência}

A Figura 3 apresenta o esquema de uma possível interpretação teórica dessa mudança de Prática Cultural (PC), utilizando os conceitos de macrocontingência e metacontingência para tal entendimento.

A Figura 3 ilustra a situação em que se encontrava o trânsito da cidade de Brasília, nos anos de 1995 e 1996, antes da mudança proposta pela Campanha do Respeito à Faixa ocorrer. Pode-se dizer que existiam duas Práticas Culturais que se caracterizavam pela recorrência e similaridade no conteúdo comportamental de vários indivíduos (Glenn, 2004): motoristas não respeitando a faixa (PC1) e pedestres não a utilizando (PC2). Essas práticas produziram um produto cultural - alto índice de atropelamento de pedestres - perigoso e prejudicial, que se configurava como um problema social que passou a ser de conhecimento público quando noticiado pelo Correio Braziliense. Essas notícias enfatizavam a violência no trânsito da cidade que culminava em altos índices de atropelamentos fatais.

O comportamento operante quase sempre envolve um produto, e esse produto define o operante específico que uma intervenção comportamental é designada a mudar. Normalmente, a razão para intervir é a não satisfação com tal produto. Quando o que está causando 


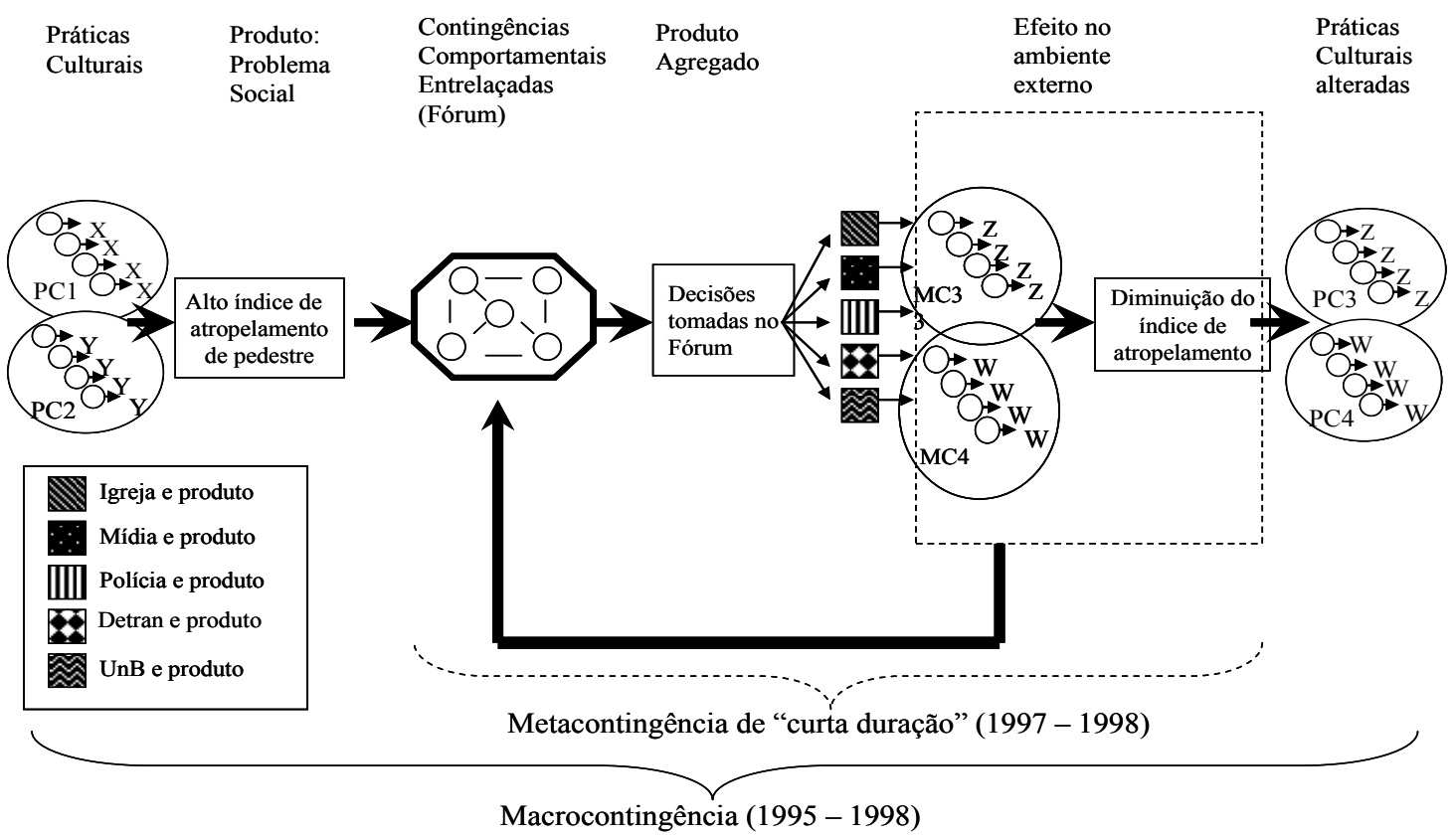

Figura 3. Esquema representativo da intervenção cultural. (PC1: Prática Cultural 1 - motoristas não respeitando a faixa; PC2: Prática Cultural 1 - pedestres não atravessando na faixa; MC3: Mudança Comportamental 3 - mudança no comportamento de motoristas; MC4: Mudança Comportamental 4 - mudança no comportamento de pedestres; PC3: Prática Cultural 3 motoristas respeitando a faixa; PC4: Prática Cultural 4 - pedestres atravessando na faixa).

insatisfação é o produto agregado de muitas pessoas se comportando, então o problema é considerado um problema cultural ou social, para o qual uma intervenção cultural pode ser necessária (Mallot \& Glenn, 2006).

No caso de Brasilia, em 1997, a fonte desse produto agregado insatisfatório, que necessitava de uma intervenção cultural, era a soma dos produtos do comportamento de muitas pessoas (motoristas e pedestres) agindo individualmente, e de forma recorrente. Vale lembrar que, mudanças no comportamento de muitos indivíduos, não necessariamente constitui uma intervenção cultural. Os vários indivíduos dos quais o comportamento é alvo, em uma intervenção cultural, são aqueles em que os comportamentos contribuem para um produto agregado insatisfatório. Não é o número de indivíduos que designa uma intervenção cultural, mas sim o produto como resultado do comportamento de vários indivíduos - funcionalmente inter-relacionados ou não (Mallot \& Glenn, 2006).
E nesse caso, a mudança comportamental de um único indivíduo não causa impacto. Assim parecia ser o caso de Brasillia-DF, em que uma intervenção cultural para diminuir, significativamente, o alto índice de atropelamentos fatais, deveria atingir o maior número possível de motoristas.

Nessa direção teórica, pode-se dizer que uma intervenção cultural, para mudar o alto índice de atropelamentos, foi proposta e acordada no Fórum Permanente pela Paz no Trânsito. As reuniões do grupo do Fórum produziam decisões sobre o que fazer com relação a este problema social, além de discutir sobre outras questões. O grupo pode ser entendido, então, como um conjunto de contingências comportamentais entrelaçadas formado pelos representantes das várias agências dele participantes. Essas pessoas se reuniam e tomavam decisões sobre as ações de cada um na sua própria agência (e.g. qual seria o trabalho da Polícia Militar, do Detran, e assim por diante), decisões essas que contituíam o produto 
agregado desse entrelaçamento.

Nesse momento, a fonte do produto agregado se caracteriza pela interação organizada e recorrente de vários indivíduos (representantes das agências), dos quais o comportamento entrelaçado resulta em um produto agregado. Depois, cada representante, na sua própria agência (que também pode ser entendida como um conjunto de comportamentos entrelaçados, mas que não é o foco da presente análise), articula ações que caracterizam o produto de cada uma das agências identificadas e analisadas no presente trabalho. Assim, pode-se sugerir o entendimento das intervenções das agências como um procedimento que articula diferentes conjuntos de contingências comportamentais entrelaçadas e seus produtos, para se promover uma mudança cultural.

O produto do Fórum (decisões tomadas) e os produtos de cada agência (aplicação das decisões) produziram um efeito selecionador no ambiente externo. Esse efeito é a Mudança Comportamental (MC) no repertório de motoristas (MC3) e pedestres (MC4), que leva a uma redução dos índices de atropelamentos.

Esse efeito parece ter sido responsável pela seleção do entrelaçamento dos representantes no grupo do Fórum, caracterizando, assim, uma metacontingência. Como afirmam Mallot \& Glenn (2006), metacontingências são relações entre contingências comportamentais entrelaçadas e seus ambientes selecionadores. Se a ação no ambiente externo, contingente ao produto da organização, funciona para manter a recorrência das contingências comportamentais entrelaçadas e seu produto, a seleção cultural está presente, selecionando uma linhagem cultural de contingências comportamentais entrelaçadas. A relação entre recorrentes contingências comportamentais entrelaçadas e seu produto, e o input mantenedor, é chamada de metacontingência.

Optou-se por denominar de Mudanças Comportamentais, o efeito no ambiente externo, porque estas só se configuram como Práticas Culturais (PC3 e PC4) ao longo do tempo, conforme os comportamentos envolvidos vão sendo recorrentes. Pode-se dizer, portanto, que a mudança de Prática Cultural foi resultante da metacontingência que deu certo: os efeitos no ambiente externo (mudanças comportamentais e redução nos índices de atropelamento) selecionaram o entrelaçamento dos representantes do grupo no Fórum e seu produto (tomada de decisões).

Essa metacontingência pode ser nomeada como de "curta duração", já que o entrelaçamento dos representantes do Fórum acabou no fim de 1998. O Fórum foi dissolvido no final de 1998, permitindo, então, poucas recorrências desse entrelaçamento. Ao longo dos anos de 1997 e 1998 esse entrelaçamento no Fórum sobreviveu e permaneceu relativamente estável, mesmo quando certas linhagens operantes de alguns indivíduos foram alteradas pela modificação de partes dos representantes. Se as contingências comportamentais entrelaçadas mantêm a recorrência suficiente dos comportamentos dos participantes substituídos, produzindo um produto agregado que satisfaça ao receptor (efeito no ambiente externo), então as contingências comportamentais entrelaçadas continuam sendo selecionadas (Mallot \& Glenn, 2006). Entretanto, no início de 1999, com a mudança do governo do Distrito Federal, muitos representantes foram substituídos e outros se desligaram do Fórum, o que alterou de forma fatal esse entrelaçamento.

A descrita metacontingência de "curta duração" pode ser interpretada como um processo de intervenção cultural para alterar uma macrocontingência, entendida como a relação entre os comportamentos recorrentes de vários indivíduos e uma produto resultante da soma dos produtos comportamentais individuais (Mallot \& Glenn, 2006). Esta Macrocontingência refere-se ao período de 1995 a 1998, caracterizado, inicialmente, pela existência de Práticas Culturais (PC1 
e PC2) que geravam um produto insatisfatório (alto índice de atropelamentos), seguido por uma intervenção cultural planejada (que envolveu o Fórum como metacontingência de curta duração) e a alteração dessas práticas culturais (PC3 e PC4). Na macrocontingência, a situação que justifica uma intervenção é o produto agregado do comportamento de muitos (PC1 e PC2) que precisou ser alterado (PC3 e PC4). Essa interpretação elucida, então, metacontingências podem ser estar embutidas em uma macrocontingência.

A partir de 1999, o Respeito à Faixa de Pedestre continuou ocorrendo em Brasilia, sendo observado até os dias atuais. O presente trabalho não teve como objetivo investigar a manutenção dessa Prática Cultural nesse período. Esta seria uma outra proposta de investigação, com o intuito de entender os processos mantenedores dessa Prática, mesmo com a ausência de uma intervenção tão estruturada e bem articulada, como foi a implementada pelo Fórum e pelas ações simultâneas das agências representadas nele.

\section{Conclusão}

O Respeito à Faixa de Pedestre, em Brasília/DF, representou um fenômeno social de sucesso, graças a uma efetiva intervenção cultural, própria e única, desenvolvida através de decisões estratégicas tomadas pelos representantes de importantes agências, do governo e da sociedade civil, reunidos no Fórum Permanente pela Paz no Trânsito, que funcionava junto à Universidade de Brasília $(\mathrm{UnB})$. Intervenção esta que mostrou a importância da integração entre governo e sociedade, mediadas pela mídia, no planejamento de mudanças culturais.

A interpretação teórica do processo de mudança da Prática Cultural do Respeito à Faixa de Pedestre, apresentada no presente trabalho, não exclui outras interpretações plausíveis acerca desse mesmo fenômeno social, pois grande parte da utilização dos conceitos de metacontingência e macrocontingência, no estudo dos fenômenos sociais, ainda requer interpretações teóricas dos fenômenos. Isso ocorre pelo fato de a grande maioria dos estudos sobre costumes culturais, como este, não ser pesquisas experimentais e por isso, não ser possível a manipulação de variáveis. Uma característica da análise comportamental das sociedades é que ela é, fundamentalmente, descritiva, ao invés de experimental.

O presente estudo é um exemplo de como experimentos em situações naturais podem ser aproveitados para novos estudos, sendo relevantes social e cientificamente. Essa pesquisa traz benefícios sociais podendo servir como modelo para novos planejamentos dessa prática em outras cidades do Brasil, como vêm ocorrendo, e científicos, ao se caracterizar como uma vertente de estudos promissora, que amplia o campo de pesquisa da Análise do Comportamento, tão concentrado em pesquisas experimentais no laboratório.

Dessa maneira, estudos como o presente trabalho ainda são um desafio para os Analistas do Comportamento, pois, como ressalta Skinner (1953/2000), “as situações práticas são quase sempre mais complexas que aquelas do laboratório, pois contêm muito mais variáveis e, freqüentemente, muitas desconhecidas. Este é o problema especial da tecnologia contra a ciência pura” (p. 472).

\section{REFERÊNCIAS}

Andery, M. A., Micheletto, N \& Sério, T.M. (2005). A análise de fenômenos sociais: Esboçando uma proposta para a identificação de contingências entrelaçadas e metacontingências. Em J. C. Todorov, R. C. Martone \& M. B. Moreira (Orgs.), Metacontingências: Comportamento, cultura e sociedade (pp. 129-147). Santo André: ESEtec.

Castro, A. C., Santos, C. S., Yamanaka, D. T. \& Rosa, P. F. (1997). Paz no trânsito: Exemplo de jornalismo cívico. Monografia, Universidade de Brasília, Brasília. 
Glenn, S. S. (1986). Metacontingencies in Walden Two. Bebavior Analysis and Social Action, 5, 2-8.

Glenn, S.S. (1988). Contingencies and metacontingencies: Toward a synthesis of behavior analysis and cultural materialism. The Behavior Analyst, 11, 161-179.

Glenn, S. S. (1989). Verbal behavior and cultural practices. Behavior Analysis and Social Action, 7, 10-15.

Glenn, S. S. (1991). Contingencies and metacontingencies: Relations among behavioral, cultural, and biological evolution. Em P. A. Lamal (Org.), Behavioral analysis of societies and cultural practices (pp. 39-73). New York: Hemisphere Publishing Corporation.

Glenn, S. S. (2004). Individual behavior, culture and social change. The Behavior Analyst, 27, 133-151.

Glenn, S. S. \& Mallot, M. E. (2004). Complexity and selection: Implications for organizational change. Behavior and Social Issues, 13, 89-106.

Huffman, K., Vernoy, M. \& Vernoy, J. (2001). Psicologia. São Paulo: Editora Atlas.

Malott, R. W. (1988). Rule governed behavior and behavioral anthropology. The Behavior Analyst, 11, 181-203.

Mallot, M. E. \& Glenn, S. S. (2006). Targets of intervention in cultural and behavioral change. Behavior and Social Issues, 15, 31-56.

Mattaini, M. A. (1995). Teaching cultural design: Shaping new behaviorists. Behavior and Social Issues, 5, 21-28.

Mattaini, M. A. (1996). Envisioning cultural practices. The Behavior Analyst, 19, 257-272.

Melo, F. B. \& Moreira, M. E. P. (2005). O pedestre como componente básico da concepção dos espaços públicos. Anais do XIV Congresso de Pesquisa e Ensino de Transportes, ANPET.

Michael, J. (1993). Establishing operations. The Behavior Analyst, 16, 191-206.

Sanabio, E. T., \& Abreu-Rodrigues, J. (2002). Regras: Estímulos discriminativos ou estímulos alteradores de função. Em H. J. Guilhardi, M. B. B. P. Madi, P.
P. Queiroz \& M. C. Scoz (Orgs.), Sobre comportamento e cognição: Contribuições para a construção da teoria do comportamento (pp. 114-119). Santo André: ESEtec

Schlinger, H. (1993). Separating discriminative and function-altering effects of verbal stimuli. The Behavior Analyst, 16, 9-23.

Skinner, B. F. (1961). The design of cultures. Daedalus, 90, 534-546.

Skinner, B. F. (1978). Walden two. (R. Moreno \& R. Saraiva Trads.) São Paulo: E.P.U. Trabalho original publicado em 1948).

Skinner, B. F. (1978). O Comportamento verbal. (M. P. Villalobos Trads.) São Paulo: Cultrix. (Trabalho original publicado em 1957).

Skinner, B. F. (1981). Selection by consequences. Science, 213, 501-504.

Skinner, B. F. (1982). Sobre o behaviorismo. (M. P. Villalobos Trads.) São Paulo: Cultrix. (Trabalho original publicado em 1974).

Skinner, B. F. (1983). O mito da liberdade. (E. R. B. Rebelo Trads.) São Paulo: Summus. (Trabalho original publicado em 1971).

Skinner, B. F. (1984). Contingências de reforço: uma análise teórica. (R. Moreno Trads.) Em V. Civita (Org.), Coleção Ospensadores (Pavlov e Skimner). São Paulo: Editora Abril. (Trabalho original publicado em 1969).

Skinner, B. F. (1986). What is wrong with daily life in the Western world? American Psychologist, 41, 568-574. Skinner, B. F. (2000). Ciência e comportamento bumano. (R. Azzi \& J. C. Todorov Trads) São Paulo: Martins Fontes. (Trabalho original publicado em 1953).

Todorov, J. C. (1987). A Constituição como metacontingência. Psicologia: Ciência e Profissão, 7, 9-13.

Vialle, C., \& Junior, W. K. (2003). Desrespeito às faixas de pedestres: O papel dos órgãos de trânsito. Anais do XVII Congresso de Pesquisa e Ensino em Transportes, ANPET.

Artigo submetido em 9 de outubro de 2008 Aceito em 21 de abril de 2009 